\title{
EXPERIMENTAL AND NUMERICAL METHOD FOR DETERMINING WOOD CHAR-LAYER AT HIGH TEMPERATURES DUE TO AN ANAEROBIC HEATING
}

\author{
E.M.M. FONSECA \& L.M.S. BARREIRA \\ Department of Applied Mechanics, Polytechnic Institute of Bragança, Portugal.
}

\begin{abstract}
This work proposes an experimental and numerical method to determine char-layer and temperature in pine wood at high temperatures. The elevated temperature in the wood is due to an anaerobic heating process. A thermal unit and electro-ceramic resistance are used during experimental tests to simulate elevated temperatures in wood profiles. Wood samples have been manufactured for experimental tests. To ensure greater efficiency in the heating process, it is necessary to insulate the wood samples. A numerical method that predicts the thermal degradation of wood exposed to high temperatures is used. A non-linear thermal and transient analysis is conducted using the finite element method. Numerical results are obtained to determine temperature fields and char-layer in wood profiles under same conditions. The char-layer is calculated for pine wood profiles (Pinus pinaster) through this study. This parameter is important in safety design because it determines how cross-section size decreases to critical external conditions. These methodologies could be used to assess the performance time of wood material, during exposure to high temperatures or in fire conditions.
\end{abstract}

Keywords: char-layer, heating process, high temperatures, pine wood.

\section{INTRODUCTION}

The wood materials present an increased use of structural engineering applications in buildings and other special engineering production. These engineering products prove to be more environmental friendly and cheaper, than other materials, such as steel or concrete. When wood structures are exposed to high temperatures, a char-layer is formed from the burned wood, which loses all strength, but insulating temperature increases in the core of the material. The charring rate is more or less constant and mainly depends on the density and moisture content of wood. The charring rate of softwood or hardwood material exposed to fire conditions based on the standard time-temperature curve has been studied by researches in different countries [1-7]. These investigations show the major influence of wood density. Some empirical models have been developed by Schaffer [1] and White [2, 3] for the determination of charring rate under heat transfer conditions. Safety rules and guidelines are useful for different wood applications. The high vulnerability of wood, due to fire conditions or elevated temperatures, requires a rigorous thermal and mechanical analysis. However, when compared with other building materials, wood material provides a good resistance to high temperatures. When wood materials are used, fire protective finishes are typically required and the protection needed can be determined based on the building codes. The main objective of this work is to present a numerical and an experimental method, which could be used to assess the performance time of wood material, during exposure to high temperatures. The char-layer determination is also obtained using these two different methods. The wood species in study is the pine material (Pinus pinaster), due to its economical importance, and it is widely used for construction, for paper industry and for resin production. For experimental method, different pine cross-sections (Pinus pinaster) are tested and submitted to high temperatures using a heating power unit based on electrical 
ceramic resistances. The temperature of the wood profile is measured during heat exposure. Using appropriate material properties and boundary conditions, reasonable predictions of char-layer by a finite element or a numerical method can be provided. The numerical analysis was conducted by a finite element method using Ansys program. Two-dimensional and three-dimensional numerical models are used for non-linear thermal and transient analyses. Wood thermal response is compared between numerical and experimental results. For experimental results, an electro-ceramic heating system is used in laboratory. All pine wood samples are prepared to ensure a greater efficiency during the heating process. The temperature evaluation, in wood cross-section, is conducted using an anaerobic heating process. A number of experimental tests are needed, in such way that allows more conclusions, about the proposed process, as referred previously by Fonseca [8].

\section{WOOD THERMAL PROPERTIES}

The wood combustion is slow and regular, and their behaviour is predictable. If wood is subjected to a sufficient heat, a degradation thermal process (pyrolysis) occurs, producing gases accompanied by loss in weight and serviceable cross-section. The thermal degradation of wood occurs in stages. The degradation process depends upon the heating rate and the temperature. The factors which affect the burning behaviour of wood will determine the charring rate. These types of factors are: level of radiant heat exposure, formation of char, moisture content, wood species and dimensions [9]. Many researchers have worked with several models for the pyrolysis in solid materials, as referred by Weng [10]. Weng [10] has evaluated the accuracy of the above pyrolysis model for charring material under different ambient oxygen concentrations. Design models of wood structures subjected to high temperatures result in the loss of cross-section due to char-layer and the temperature-dependent reduction of strength and stiffness of the non-charred residual cross-section [11]. The strength and stiffness of wood significantly decrease with increasing temperature [12]. The interface between charred and non-charred wood is the demarcation plane between black and brown material, characterised by a temperature of $300^{\circ} \mathrm{C}$ [13]. The charring rate for different types of species exposed to the standard time-temperature curve has been studied in different countries by many researchers [14-16].

Wood is classified into two different types. The softwoods and hardwoods indicate the basic cellular structure and how moisture moves within the living tree. Softwoods generally come from the coniferous species (pines, firs and spruces, for example) and are generally fine textured. Hardwoods (eucalypts and oaks, for example) have broad leaves and the texture ranges from fine to coarse. The types of wood include softwoods, hardwoods and glued laminated woods (glulam), in the forms of solid wood, plywood and wood-based panels. Due to large variation, type and wood quality, a system of strength classes has been established. Each grade of classification is a function of physical and wood properties.

The thermal properties of wood are strongly affected by temperature and moisture content levels. The moisture content of the wood is affected by the temperature and relative humidity of the environment where the wood is stored. The thermal behaviour of wood is complex, but has been well documented. Annex B of Eurocode5, EC5 [13], provides the design values for density, thermal conductivity and specific heat of wood. The value below $350^{\circ} \mathrm{C}$ represents the properties of wood and above $350^{\circ} \mathrm{C}$ represents the properties of charlayer.

The following figures represent the evaluation of the thermal conductivity, the specific heat and the density of wood, assuming initial moisture of $12 \%$, dependent of temperature. 
In Fig. 1 the values of the wood thermal conductivity are presented as temperature dependent. The low thermal conductivity of wood reduces the rate at which heat is transmitted inside the wood.

The specific heat for wood and carbonised layer is temperature dependent, according Fig. 2. The heat capacity of wood materials can be assumed constant for any wood. The peak verified for a value equal to $100^{\circ} \mathrm{C}$ is related to moisture wood evaporation.

Moisture in wood affects mass and volume. Density is presented in $\mathrm{kg} / \mathrm{m}^{3}$ for each specified condition. The wood strength has direct correlation with the density. Many studies have shown that the density has a significant effect on the burning rate [16]. The design values of softwood density for standard fire exposure are given in Fig. 3. These values are presented for pine material with an initial value of density, at room temperature, equal to $509 \mathrm{~kg} / \mathrm{m}^{3}$, as reported by White [12].

\section{DESIGN EQUATIONS FOR CHAR-LAYER DETERMINATION DUE TO FIRE CONDITIONS}

When a cross-section of wood burns, at a constant rate of heat release per unit area, the boundary between the pyrolysed material and the core wood (designated by pyrolysis front) proceeds to the centre of the wood. Since all pyrolysing woods are considered to char, the charring rate corresponds to the propagation rate of the pyrolysis front. This parameter is an essential quality for fire safety, because the wood under the char-layer preserves its original properties. A pyrolysis model was developed to predict the charring rate and temperature distribution in wood elements exposed to fire conditions by Janssens [17]. Other researchers have also studied the wood pyrolysis phenomena and the charring rate [2, 3, 12, 18, 19]. Important factors for the charring rate of wood are the density, the external heat flux and the moisture content. Charring rate decreases with increasing density and increases linearly with the external heat flux [15].

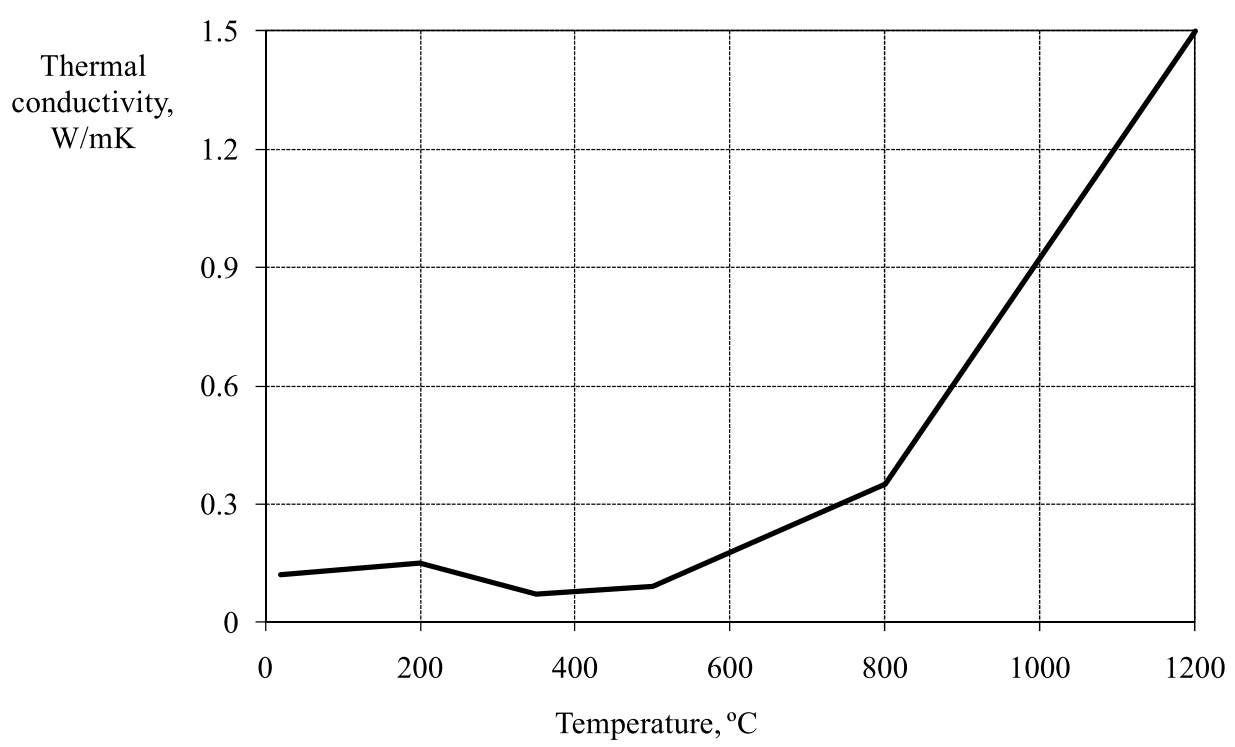

Figure 1: Thermal conductivity, EC5 [13]. 


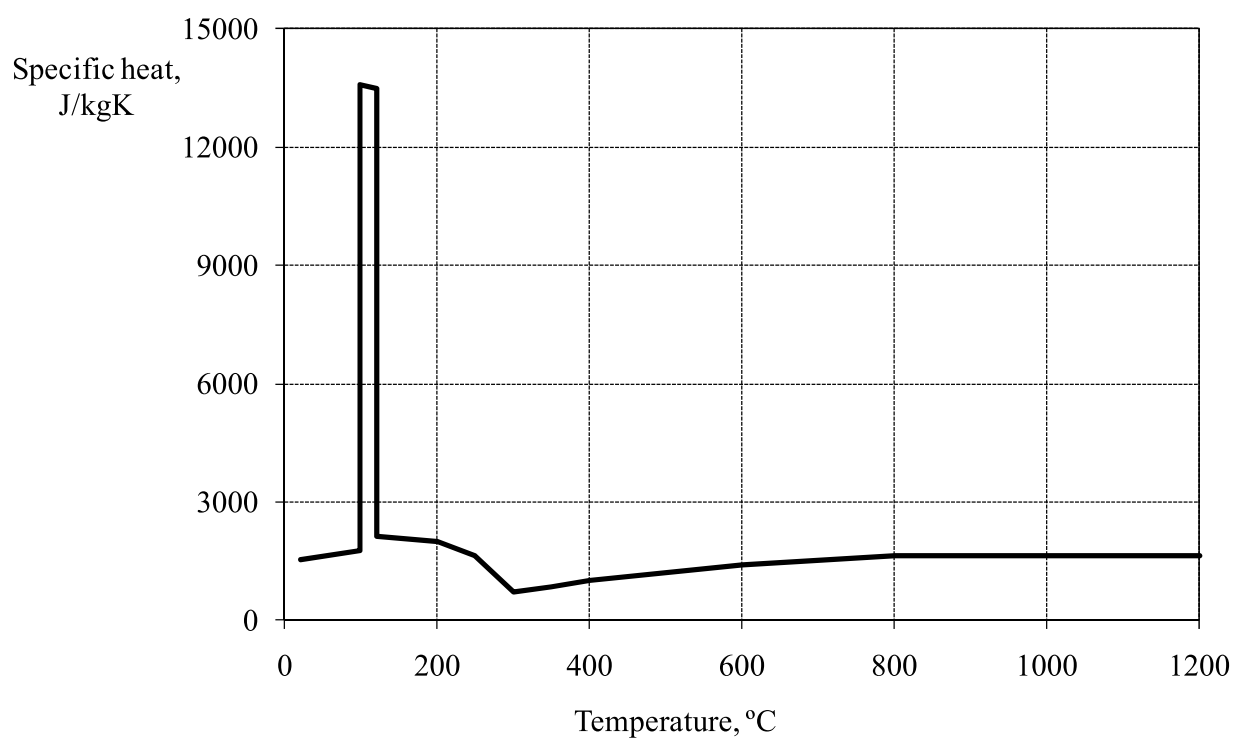

Figure 2: Specific heat, EC5 [13].

Density
$\left[\mathrm{kg} / \mathrm{m}^{\wedge} 3\right]$

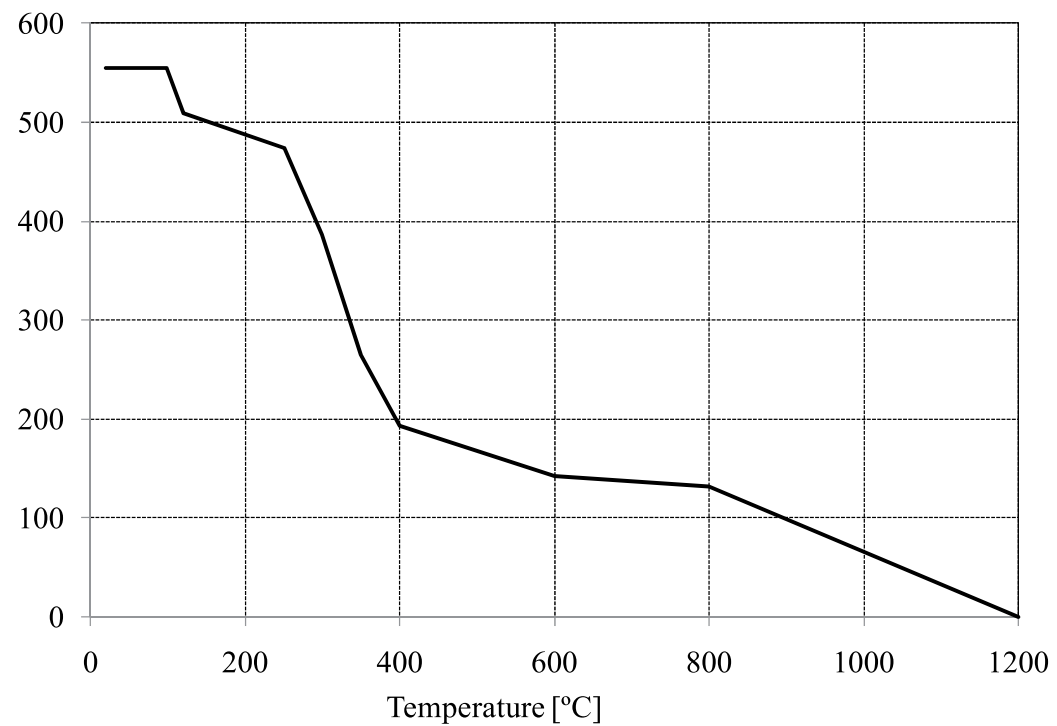

Figure 3: Density, EC5 [13].

There are typical values for charring rate of wood between 0.5 and $1.0 \mathrm{~mm} / \mathrm{min}$. EC5 [13] for wood design suggests a charring rate of $0.64 \mathrm{~mm} / \mathrm{min}$ for softwoods and $0.54 \mathrm{~mm} / \mathrm{min}$ for hardwoods. EC5 allows the use of simplified and advanced methods for the calculation of amount of char-layer in wood material. This method is a conduction model based on thermal properties of wood. Following EC5 [13], the design equation proposed for one direction 
char-layer determination, function of the charring rate for non-protected surfaces to normalised fire conditions, is presented in eqn (1).

$$
d_{\text {char }, 0}=\beta_{0} t
$$

where $d_{c h a r, 0}$ is the char depth in $\mathrm{mm}, \beta_{0}$ is the design charring rate for one-dimensional charring on fire exposure in $\mathrm{mm} / \mathrm{min}$ and $t$ is the time in min.

When the propagation of fire conditions is more than one direction, eqn (2) should be used.

$$
d_{\text {char, },}=\beta_{n} t
$$

where $d_{\text {char }, n}$ is the char depth in $\mathrm{mm}, \beta_{n}$ is the design charring rate under standard fire exposure in $\mathrm{mm} / \mathrm{min}$ and $t$ is the time in $\mathrm{min}$.

Table 1 represents design values of the charring rate for softwood, according the EC5 [13].

White and other researchers $[2,12]$ proposed different analytical equations for charlayer determination. White performed extensive measurements in different species due to fire conditions and proposed different charring rate coefficients, dependent of physical characteristics of wood. The analytical equations presented here solve problems due to fire conditions. When wood materials are subjected to high temperatures, due to an anaerobic process, the char-layer evaluation and the charring rate are different. Following chapters show two different methods to find the char-layer evaluation due to an anaerobic process.

\section{NUMERICAL METHOD}

A finite element program Ansys was used to design and analyse the thermal behaviour of pine wood profiles exposed to high temperatures. A finite plane element (Plane 77) and solid element (Solid70) were used for thermal and non-linear transient analysis. The non-linearity due to the material properties, thermal dependence is taken into account in the numerical method. Temperature is determined at 1-h duration, using a transient and thermal analysis. Thermal analysis is performed over specimens with $500 \times 180 \times 80 \mathrm{~mm}$ dimensions, as experimental procedure.

\subsection{Results with numerical method}

Figure 4 represents the used mesh and temperature evaluation obtained with the numerical method. An initial wood temperature equal to $16^{\circ} \mathrm{C}$ was considered, as measured in laboratory. A prescribed temperature was imposed on the surface top of wood simulating high

Table 1: Charring rate of softwood, EC5 [13].

\begin{tabular}{lcc}
\hline Material & $\beta_{0}(\mathrm{~mm} / \mathrm{min})$ & $\beta_{n}(\mathrm{~mm} / \mathrm{min})$ \\
\hline Glued laminated wood with $\rho \geq 290, \mathrm{~kg} / \mathrm{m}^{3}$ & 0.65 & 0.7 \\
Solid wood with $\rho \geq 290, \mathrm{~kg} / \mathrm{m}^{3}$ & 0.65 & 0.8 \\
\hline
\end{tabular}

$\beta_{0}-$ design charring rate for one-dimensional charring on fire exposure; $\beta_{n}-$ design notional charring rate under standard fire exposure; $\rho$-density. 

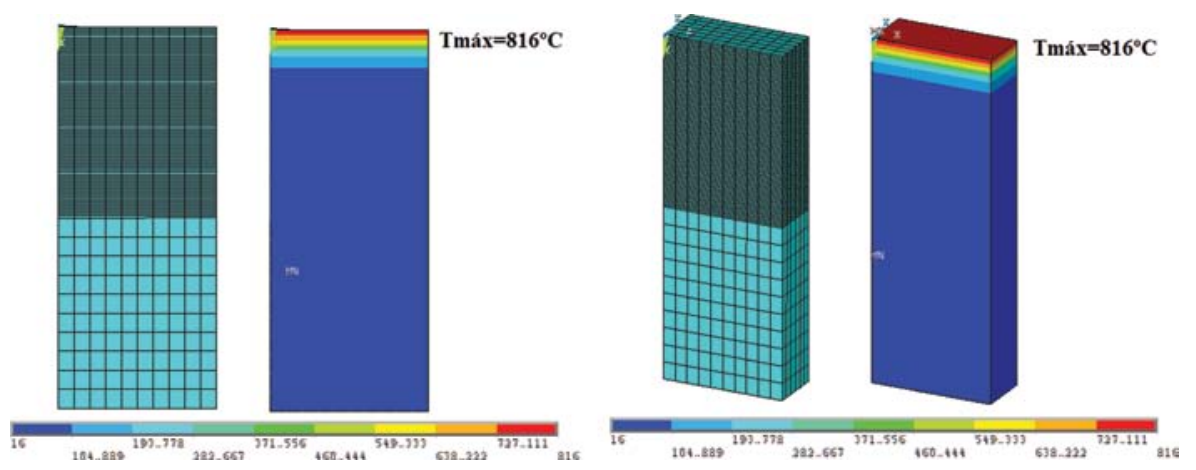

Figure 4: Plane and solid numerical method. Temperatures field at $1 \mathrm{~h}$.

temperature evaluation due to an anaerobic heating. The prescribed temperature, at wood surface top, is function of an imposed linear heating rate following the equation:

$$
T_{\infty}=T_{i}+\frac{800}{3600} t
$$

where $T_{\infty}$ is the prescribed temperature and $T_{i}$ is the initial temperature. In this equation $800^{\circ} \mathrm{C} / \mathrm{h}$ represents the heating rate and $t$ is the time in seconds.

The numerical model submitted at high temperatures presents a maximum temperature equal to $816^{\circ} \mathrm{C}$, in the warm surface, at the end of $1 \mathrm{~h}$. The results are equal using plane or solid mesh. The numerical results of the temperature evolution during heat exposure, through different measured points, are presented in Fig. 5.

In observation, at $300^{\circ} \mathrm{C}$, the positions at 1 and $2 \mathrm{~cm}$ present a char-layer for different time instants. During $1 \mathrm{~h}$ high temperature exposure the positions at 3 and $5 \mathrm{~cm}$ present a lowest value of temperature and represent a normal core wood. These results are compared with the experimental methodology using different manufactured samples. As referred by Barreira [16], the burning behaviour of wood will affect the charring rate. The charring rate is more rapid initially but stabilises after the formation of a few millimetres of char.

\section{EXPERIMENTAL METHOD}

For experimental methodology, an electro-ceramic heating system is used with a thermal power unit of $70 \mathrm{kVA}$. A typical heating curve, eqn. 3, was used and a programmable controller verifies the temperature during each experimental test. Figure 6 shows the experimental setup used in laboratory. To ensure greater efficiency in the heating process, it is necessary to insulate the wood samples. The insulation is a ceramic fibre material with stainless steel mesh, as shown in Fig. 6 . The test is performed for $1 \mathrm{~h}$ and shows the final configuration, as presented in Fig. 6.

In the present work, 18 samples of pine wood (Pinus pinaster) (T1, T2, .. T18) were submitted to high temperatures for one side exposure, as represented in Fig. 7. The charlayer was measured in five different points $(1,2,3,5$ and $25 \mathrm{~cm})$ using $\mathrm{K}$ thermocouples through an MGCPlus data acquisition system, from the heating exposure surface. The final stage of each test is represented in Figs 6 and 7, after $1 \mathrm{~h}$ exposure at high temperature. There are three different zones in all tested profiles: a charcoal zone, a pyrolyse zone and an intact core wood. 


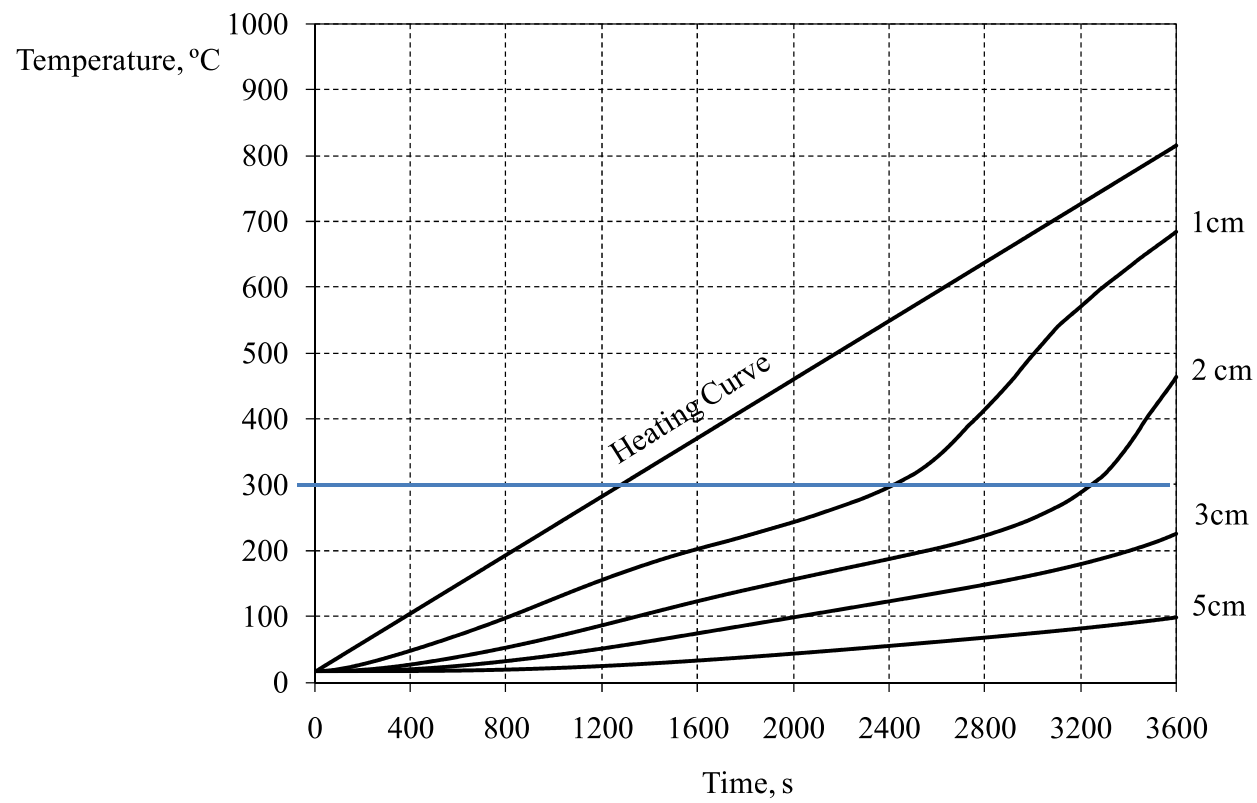

Figure 5: Temperature-time history for different measured points.
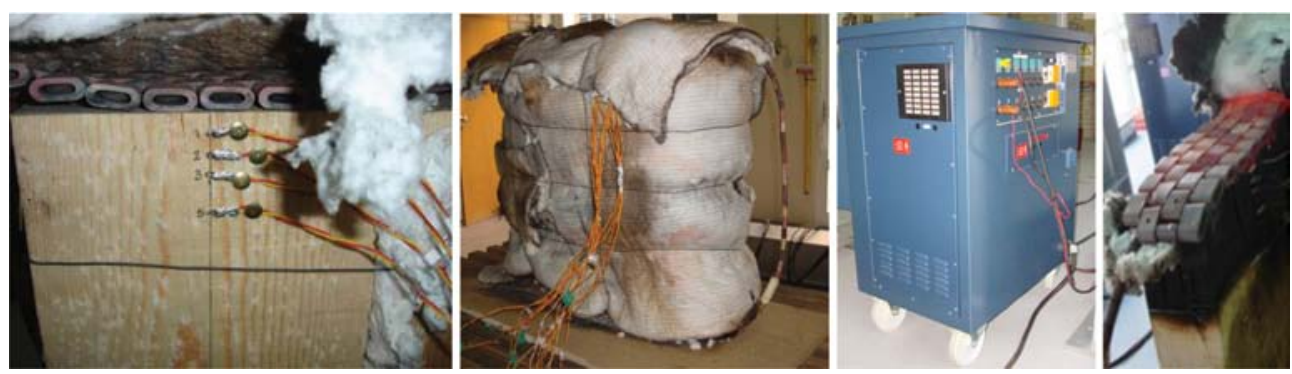

Figure 6: Experimental setup: electro-ceramic resistances, insulation, thermal unit and final test.
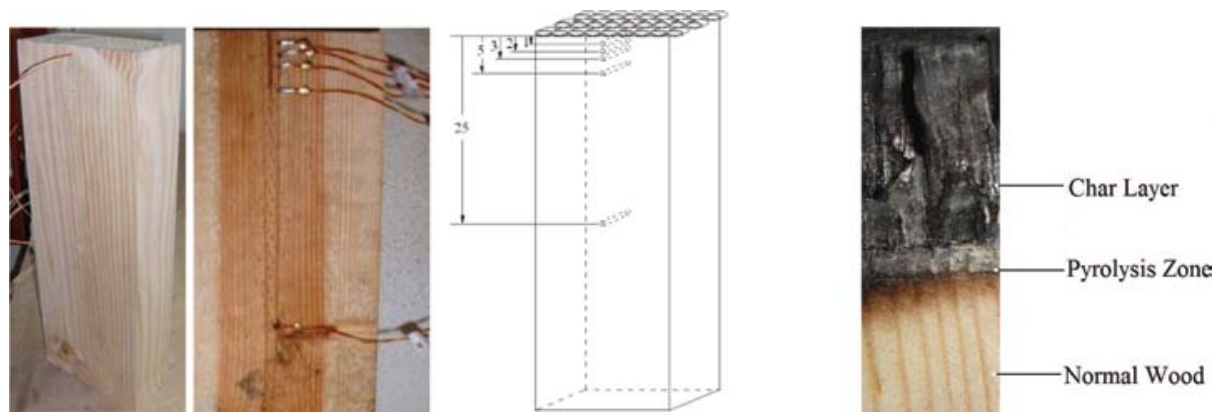

Figure 7: Experimental tests: points of measure and wood char-layer. 
5.1 Results with experimental method

Figures 8-11 represent the temperature evaluation obtained during $1 \mathrm{~h}$ in wood profiles at high temperature exposure. The results were obtained through measure points to identify the char-layer formation. The experimental results are compared with the numerical results. In all figures the temperature-time curve is also represented.

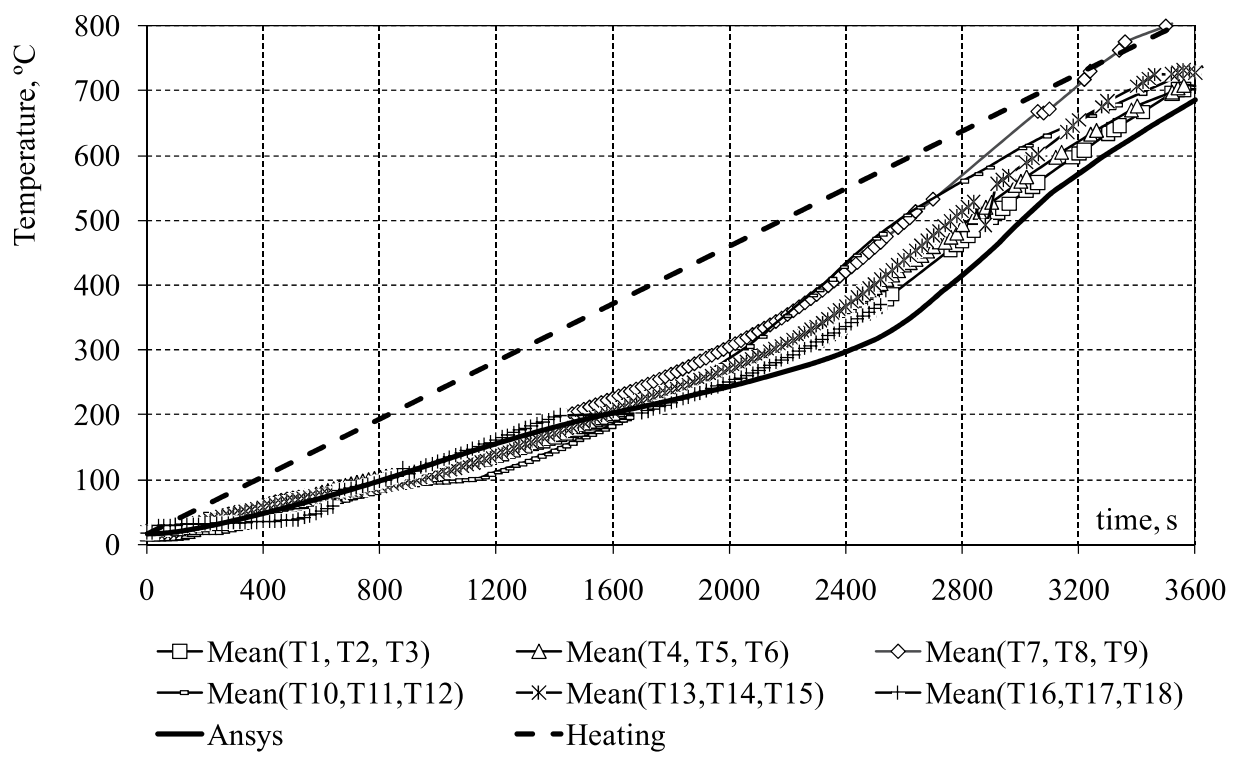

Figure 8: Temperature at $1 \mathrm{~cm}$ from top surface.

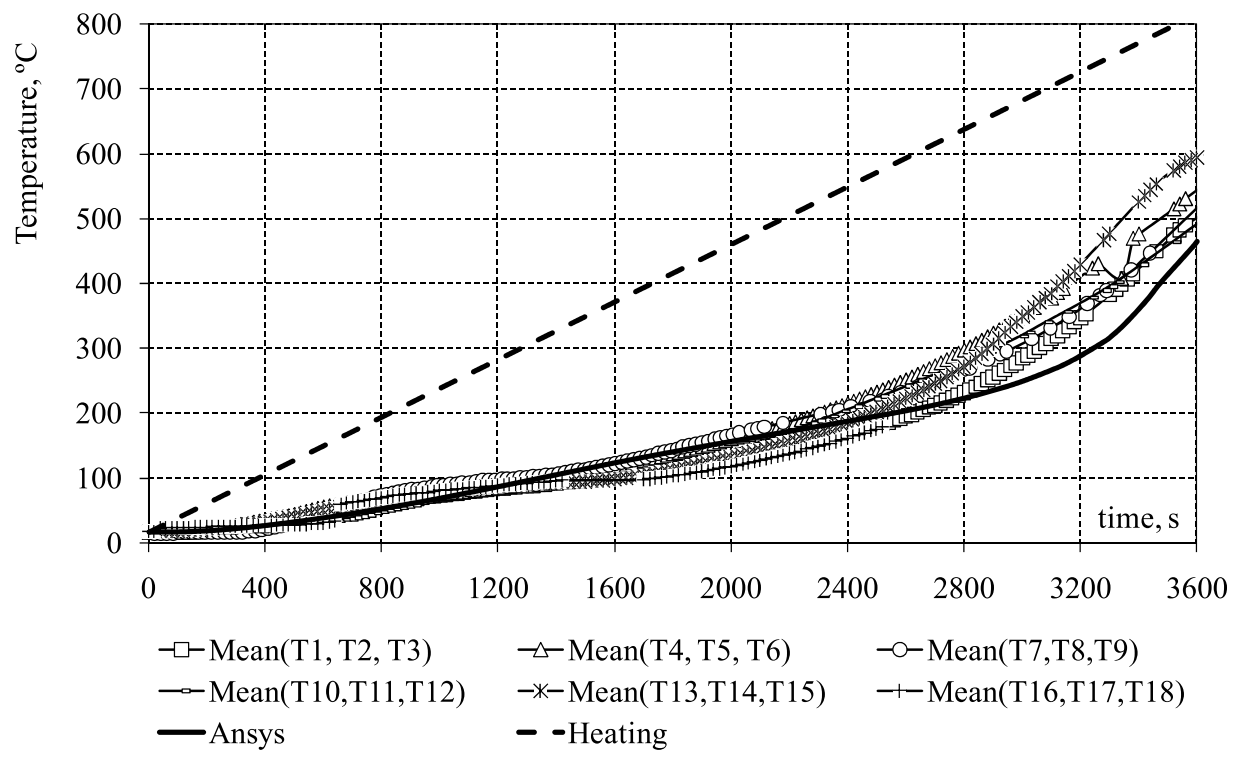

Figure 9: Temperature at $2 \mathrm{~cm}$ from top surface. 


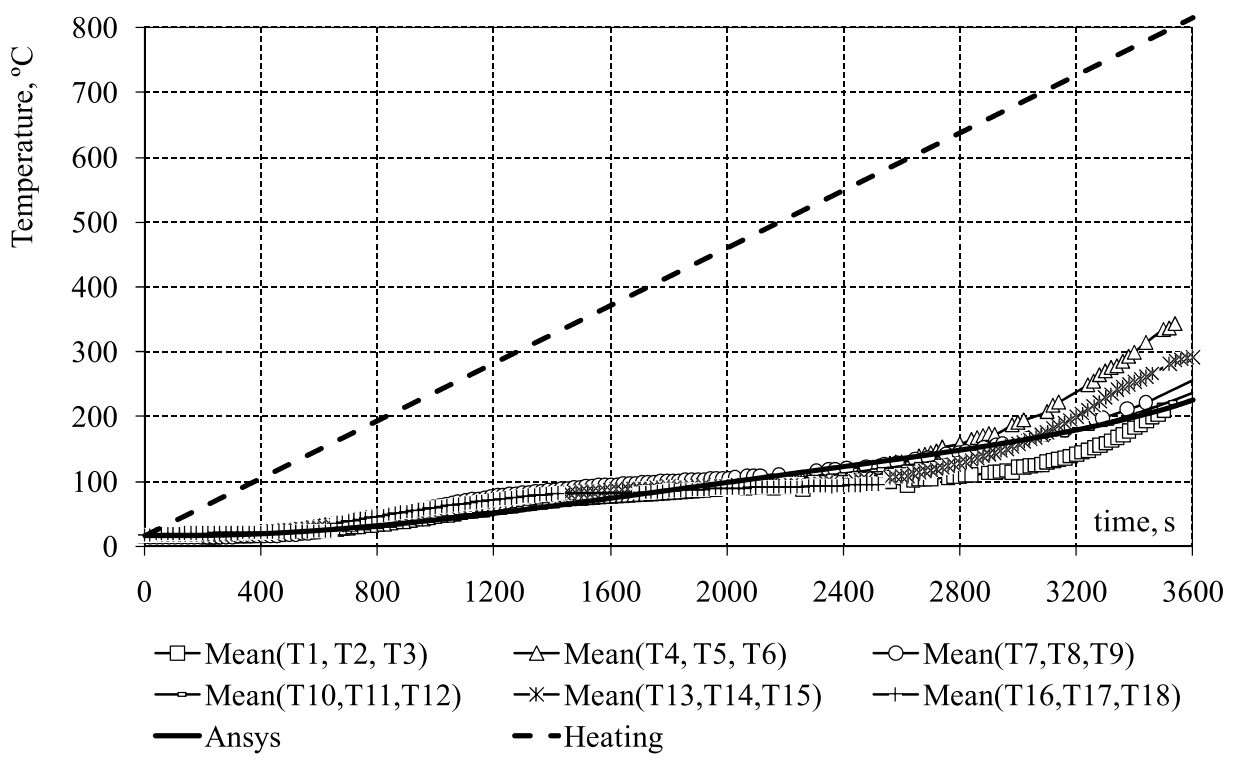

Figure 10: Temperature at $3 \mathrm{~cm}$ from top surface.

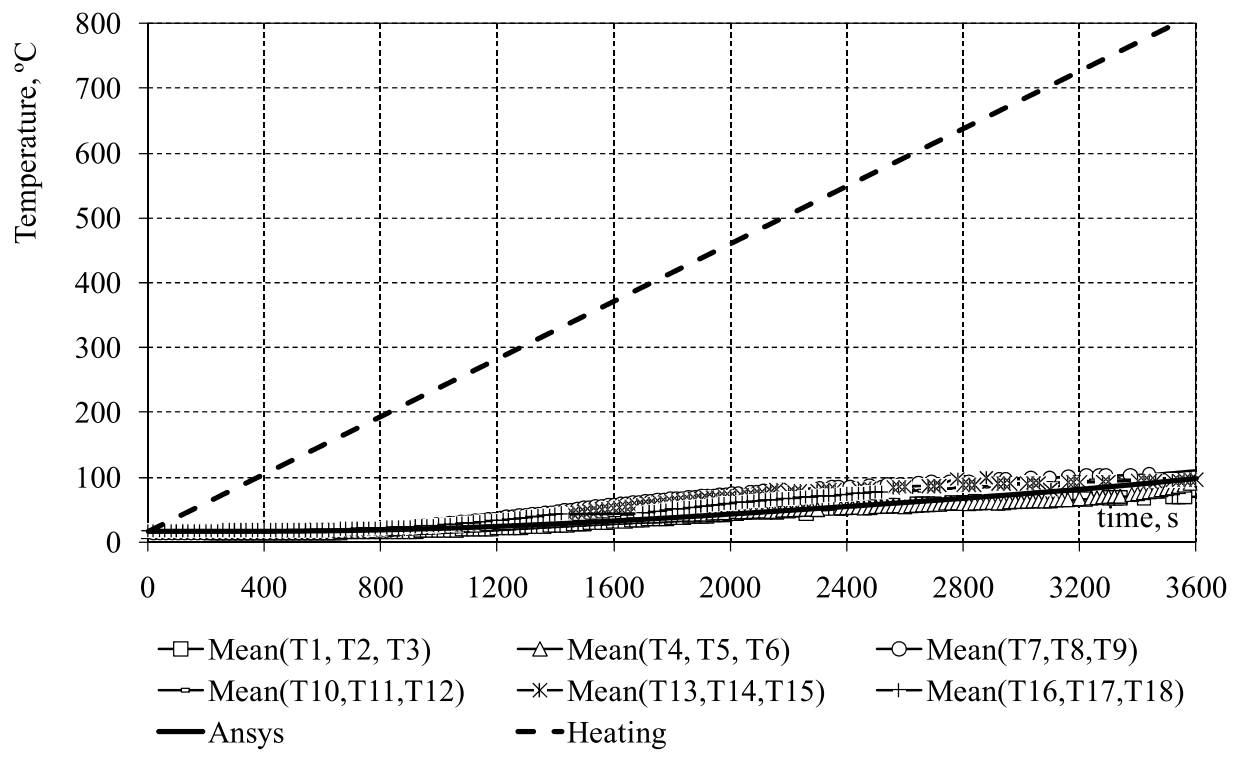

Figure 11: Temperature at $5 \mathrm{~cm}$ from top surface.

After $2000 \mathrm{~s}$ of high temperature exposure at $1 \mathrm{~cm}$ position, from top surface, a wood charcoal is obtained. At this position after $1 \mathrm{~h}$, the temperature was between 700 and $800^{\circ} \mathrm{C}$ for different experimental tests. The obtained temperatures are lesser than the heating unit power curve. On the other hand, the experimental results have higher values when compared with numerical results. 
Table 2: Temperature in different wood positions, at $1 \mathrm{~h}$.

\begin{tabular}{lcc}
\hline Position, cm & Numerical method & Experimental method \\
\hline 1 & 685 & 734 \\
2 & 464 & 510 \\
3 & 226 & 283 \\
5 & 99 & 95 \\
25 & 16 & 16 \\
\hline
\end{tabular}

At the $2 \mathrm{~cm}$ position from top surface, wood is charcoal after $2800 \mathrm{~s}$. At this measured point after $1 \mathrm{~h}$, the temperature was between 500 and $600^{\circ} \mathrm{C}$. The experimental results are higher when compared with numerical results, as in previous result.

At $3 \mathrm{~cm}$ from top surface, and before $1 \mathrm{~h}$, temperature was still below $300^{\circ} \mathrm{C}$ (Fig. 10). At this position and time, wood is non-charred.

The measured point at $5 \mathrm{~cm}$ had low temperature during $1 \mathrm{~h}$ exposure to heat, and the heat inside wood profile decreased, as shown in Fig. 11.

The measured point at $25 \mathrm{~cm}$ from top surface, cross-sections remain at normal environment temperature during all time tests.

\section{COMPARISON OF RESULTS}

Table 2 compares the numerical and experimental results of temperatures in different charlayer wood positions, after exposure of heat for $1 \mathrm{~h}$. The experimental results presented are the mean values of all tests realised.

The results show an agreement between the two alternative methods. In the first three positions, difference between the temperature values is greater. The difference verified can be due to the use of thermal properties in accordance with the proposed in EC5 [13] for fire conditions. The numerical results presented are dependent on the material properties such as thermal conductivity, density and specific heat, according to EC5 [13]. For a better comparison, some of these properties, namely the density and moisture content, should be directly measured from used pine wood material. The density is not only dependent on the species but also vary within individual tree [10]. Consequently, the moisture is also affected by the density. In the experimental results, the heat absorption by moisture has been considered, and more heat must be conducted in the charcoal material, which means higher temperatures, as referred by Weng [10], when studied the experimental temperature profile in lower ambient oxygen concentration with pine material. This effect is not represented in the numerical model. These reasons justify the difference between the first positions.

\section{CONCLUSIONS AND FUTURE WORK}

This work contributes with an experimental or a numerical alternative method for char-layer thickness evaluation in wood elements under high temperatures using an anaerobic heat process. Wood exposed to high temperatures will decompose to provide an insulating char-layer that retards further degradation. High temperatures reduce the dimensions of wood crosssections in addition to the strength and stiffness of the heated zone. The thermal depth penetration increases with increasing exposure to high temperatures and duration. In all tested profiles there are three different zones to consider: a charcoal zone, a pyrolyse zone and an intact core wood. Char-layer thickness and temperature distribution were calculated 
with numerical results obtained from Ansys program, and compared with experimental tests at same conditions. In future work, the authors intend to study the experimental effect in wood members using an oven which permits to simulate the standard fire curve. Another future aim is to verify the fire influence in char-layer formation in parallel and normal wood grain direction.

\section{REFERENCES}

[1] Schaffer, E.L., Charring Rate of Selected Woods Transverse to Grain. Research paper FPL 69. Forest Products Laboratory: Madison (WI), 1967.

[2] White, R.H., Charring Rates of Different Wood Species. PhD Dissertation, Madison University of Wisconsin, Madison (WI), 1988.

[3] White, R.H., Erik, V. \& Nordheim, E.V., Charring rate of wood for ASTM E119 exposure. Fire Technol, 28(1), pp. 5-30, 1992. doi:10.1007/BF01858049

[4] Konig, J. \& Walleij, L., One-dimensional charring of timber exposed to standard and parametric fires in initially unprotected and postprotection situations. Swed Inst Wood Technol Res, 48, 1999.

[5] Gardner, W.D. \& Syme, D.R., Charring of glued-laminated beams of eight australiangrown timber species and the effect of $13 \mathrm{~mm}$ gypsum plasterboard protection on their charring. N.S.W. Technical report no. 5. Sydney, 1991.

[6] Collier, P.C.R., Charring rates of timber. Study report, Branz, New Zealand, 1992.

[7] Pun, C.Y., Seng, H.K., Midon, M.S. \& Malik, A.R., Timber design handbook. FRIM, Malayan Forest Records no. 42, 1997.

[8] Fonseca, E.M.M. \& Barreira, L., Charring Rate Determination of Wood Pine Profiles Submitted to High Temperatures. Third International Conference on Safety and Security Engineering, ed. M. Guarascio, C.A. Brebbia \& F. Garzia, WIT Press: Italy, pp. 449-457, 2009. ISBN: 978-1-84564-193-1.

[9] Poon, L. \& England, J.P., Literature Review on the Contribution of Fire Resistant Timber Construction to Heat Release Rate - Timber Development Association, Warrington Fire Research Aust. Pty. Ltd., Project No.20633, version 2b, pp. 1-78, 2003.

[10] Weng, W.G., Hasemi, Y. \& Fan, W.C., Predicting the pyrolysis of wood considering char oxidation under different ambient oxygen concentrations. Combustion and Flame, 145, pp. 723-729, 2006. doi:10.1016/j.combustflame.2005.12.016

[11] Frangi, A., Erchinger, C. \& Fontana, M., Charring model for timber frame floor assemblies with void cavities. Fire Safety Journal, 43, pp. 551-564, 2008. doi:10.1016/j. firesaf.2007.12.009

[12] White, R.H. \& Dietenberger, M.A., Fire Safety, Chapter 17, Wood Handbook: Wood as an Engineering Material, Forest Products Laboratory, USDA Forest Service, 1999.

[13] [EN 1995-1-2] prEN 1995-1-2. Eurocode 5: Design of Timber Structures, Part 1-2: general-structural fire design, CEN, Brussels, 2003.

[14] Njankouo, J.M., Dotreppe, J.C. \& Franssen, J.M., Fire resistance of timbers from tropical countries and comparison of experimental charring rates with various models. Construction and Building Materials, 19, pp. 376-386, 2005. doi:10.1016/j.conbuildmat.2004.07.009

[15] Hakkarainen, T., Mikkola, E., Östman, B., Tsantaridis, L., Brumer, H. \& Piispanen, P., InnoFireWood-Innovative Eco-efficient High Fire Performance Wood Products for Demanding Applications, VTT, SP Trätek, KTH, 2005. 
[16] Barreira, L. \& Fonseca, E., Cálculo da Espessura Carbonizada em estruturas de Madeira Quando Submetidas à Acção do Fogo, II Conferência Nacional de Métodos Numéricos em Mecânica de Fluidos e Termodinâmica'08, Proceedings, Aveiro, 2008.

[17] Janssens, M.L., Modeling of the thermal degradation of structural wood members exposed to fire. Fire and Materials, 28, pp. 199-207, 2004. doi:10.1002/fam.848

[18] Spearpoint, M. \& Quintiere, J., Predicting the burning of wood using an integral model. Combustion and Flame, 123, pp. 308-325, 2000. doi:10.1016/S0010-2180(00)00162-0

[19] Bamford, C., Crank, J. \& Malan, D., The combustion of wood, Part I. Proceedings of the Cambridge Philosophical Society, 42, pp. 166-182, 1946. doi:10.1017/ S030500410002288X 